\title{
Ska y memoria: Hacia un recuento histórico y social del ska costarricense
}

Recibido: 1 de octubre 2020 Revisado: 8 de junio 2021 Aprobado: 5 de julio 2021

Jessica Dixiana Álvarez López Costarricense. Licenciada en Antropología Social, ProDUSUniversidad de Costa Rica, San José Costa Rica. Investigadora independiente. Actualmente cuenta con experiencia en procesos participativos, integración comunitaria, ordenamiento territorial, consulta ciudadana, gestión sociocultural, acción social, entre otros. Correo electrónico: jessicadixiana@gmail.com.

Fernando Obando Reyes Cosstarricense. Licenciado en Antropología Social y Bachiller en Ciencias de la Comunicación Colectiva con énfasis en comunicación audiovisual y multimedial. Comunicador e investigador social del Centro

Agenda Joven en Derecho y Ciudadanía, de la Universidad Estatal a Distancia, San José Costa Rica. Actualmente trabaja en temas que abordan cuestiones como: juventud y política pública, tecnologías de la información y comunicación, gestión cultural

musical y politica educativas. Correo electrónico: fjor09@gmail.com
Resumen: Este artículo presenta una contextualización de la historia de la música ska en Costa Rica, la cual se encuentra estrechamente ligada con "la tercera ola de ska" a nivel mundial y el desarrollo de los otros géneros musicales en la década de los 90 en el país. Durante este período se destaca la participación de agrupaciones jóvenes de los "barrios del sur" de San José y otras partes de la Gran Área Metropolitana. A modo de discusión, las personas investigadoras muestran una serie de anotaciones que buscan brindar guía al estudio de la música ska en el país, desde su contexto histórico hasta su importancia a nivel social.

Palabras clave: ska, conciertos, música, historia

\section{Ska and Memory: A Social and Historical Headcount of the Costa Rican Ska}

\begin{abstract}
This paper presents a contextualization of the history of ska music in Costa Rica, which has a narrow link with the "third wave of ska" at a worldwide level and the development of other music genres in the decade of the 90's in the country. During this period the participation of groups with young people from the neighborhoods from the south of San José Downtown and other parts from the Great Metropolitan Area it's a big highlight. In a sense of discussion, the researchers show a series of annotations that try to find guidance to study of ska music in the country, from its historical context to its importance at a social level.
\end{abstract}

Key words: Ska, Concerts, Music, History 


\section{Introducción}

Una canción de la banda costarricense La Milixia dice: "La multitud nos nota al caminar / Es que compartimos una misma historia, nuestro ska, calle y memoria. / Siempre queda en la memoria, aquellos días, aquellas glorias / es que hay momentos llenos de emoción, de tristezas, sueños e ilusión." (La Milixia, Ska, Calle y Memoria, d'CRock Records, disco compacto, 2011). Aquí el ska es más que un género musical, es un espacio de encuentro, de convivencia, pero sobre todo de memoria e historia que se dio en contextos y lugares específicos, los cuales influyeron en como las personas se apropiaban y promocionaban un género musical con el que podían expresarse y compartir con sus pares.

Es así como el presente artículo pretende visibilizar, pero sobre todo contextualizar, analíticamente, la trayectoria histórica que ha tenido el ska (o ska fusión como se verá más adelante) tanto a nivel mundial como local, con el fin de visibilizar la herencia musical que tuvo (y sigue teniendo) este género musical dentro del contexto nacional, más cuando, con el ska se goza de la particularidad de contar con un público joven y una cantidad de bandas que reclamaban continuamente un espacio para la expresión, el arte y la cultura; por eso dicha contextualización histórica se realizó desde los testimonios de quienes vivieron y construyeron los espacios para el fomento del ska.

Aquí es necesario señalar que se delimitó la contextualización al género musical ska dado que ya en Costa Rica había investigaciones de ciencias sociales sobre géneros como metal, punk, reggae, swing criollo, entre otros, por lo que la presente investigación constituyó un aporte nuevo en relación con el tema.

Aunando a lo anterior, se tiene que estudiar el ska constituía una forma de vislumbrar cómo se desarrollaba la escena musical alternativa e independiente de un género musical específico en el contexto costarricense.

Cabe mencionar que, dada las particularidades de la investigación y la práctica antropológica, es necesario realizar un acercamiento integral del fenómeno en estudio (en este caso de la escena del ska); esto implica que la investigación no solo se concentre en el abordaje de las dinámicas sociales actuales del grupo, sino que también se profundice en cuestiones como lo son los antecedentes o la forma en que nace dicho fenómeno, información que está allí pero constituye un registro disperso. Aquí la historia del ska (y de la escena musical en general) muestra datos sobre la dinámica de un grupo de personas, formas de socializar ciertos elementos, producción artística de una época determinada, entre otros. Es decir, la contextualización del género musical se vuelve una herramienta para mapear y entender la transformación de 
la música local y como esta impacta en la realidad actual, que en parte es el aporte del presente artículo.

El presente artículo formó parte del trabajo de investigación para optar por el grado de licenciatura realizado por los autores, cuyo objetivo principal fue comprender cómo operaba la gestión cultural en los chivos de ska-fusión en el área metropolitana de San José. Uno de los capítulos trabajados fue la contextualización histórica del ska.

Durante el proceso investigativo, se observó como los conciertos eran (y siguen siendo) espacios que iban más allá de la mera exposición musical, aquí se daban algunas interacciones y dinámicas sociales, a las que se les daba un significado particular, esto por parte de quienes asistían a dichas actividades. Pero para entender dichos significados, es que surgió también la necesidad de vislumbrar cómo la historia local del ska, tanto a nivel mundial como nacional, influyó significativamente en la manera en que se desarrollaban e interiorizaban algunos de los conciertos; así como este género empezó a ser visible en algunos contextos cotidianos de algunos jóvenes.

Se considera pertinente aludir a las siguientes conceptualizaciones pues estas conservan un estrecho ligamen con las posturas teóricas desarrolladas por las personas autoras durante el proceso de investigación. La primera de ellas remite al término "gestión cultural" entendida como aquella que "contempla la propuesta, logística, organización y el incentivo de actividades, las cuales son una respuesta y forma de hacer valer el derecho a la cultura (en sus múltiples manifestaciones). Autores como Zubiría, Abello y Tabares $(1998,19)$ comentan que la gestión cultural puede considerar como objetivo prevenir que la cultura caiga en lo inanimado, "intenta aportar herramientas de conocimiento y de educación artística para enriquecer la creatividad personal y de las comunidades" $(1998,19)$.

Del mismo modo, al discutir respecto a la "escena musical" o "la escena", debe entenderse esta como un "grupo de actores (proyectos musicales, espacios culturales, medios especializados, gestores, productores, entre otros agentes del sector) vinculados a un determinado momento sociopolítico y a un territorio en particular en el que comparten ciertos intereses comunes" (Recalculando 2017,94).

Finalmente, se cree que para entender el desarrollo del ska y su interacción histórica con otros ritmos tanto a nivel local como internacional, es pertinente rescatar la noción de "género musical", la cual según el planteamiento de Dannenberg (2010) es una forma de categorizar estilos musicales particulares, tomando en cuenta que dicha acción es influenciada por convenciones sociales, marketing, influencia externa o asociaciones dirigidas a un artista en específico. 


\section{Metodología}

Las técnicas utilizadas para la construcción de este artículo se detallan a continuación:

\section{Entrevista}

La entrevista a profundidad permitió ver como se fue desarrollando la escena del ska y con ello, la importancia que iban teniendo algunas actividades de este género. Para ello se realizó un instrumento donde se contemplaron preguntas abiertas sobre temas como historia, conciertos, espacios donde se compartía música, significados, entre otros. Estas fueron realizadas a personas que, de una u otra forma, se han involucrado en el inicio y fomento de este género musical, realizándose así 22 entrevistas durante el 2013 y 2014.

Cabe mencionar que la contextualización histórica que se presentara en los próximos apartados, constituye una sistematización de todas estas entrevistas, sin embargo, solo se presentan las citas textuales de tres de ellas, las cuales se consideran de vital importancia por la cercanía de los actores a la escena del ska desde sus inicios (Álvarez y Obando 2018).

\section{Revisión Bibliográfica}

La revisión bibliográfica fue fundamental en la construcción histórica del ska, especialmente en lo referente al inicio de este a nivel mundial. Aquí se trabajó con documentos los siguientes documentos:

1. Libros y revistas académicas: que abordaban el contexto histórico del ska, tanto a nivel mundial como en Costa Rica.

2. Tesis de grado: las cuales comprendían el abordaje de algunos géneros musicales como: punk (Fuentes 2004), ska (Carballo 2001) (Carballo 2006), rock (Zúñiga 2006) y metal (Corrales 2011). Siendo abordados desde su contextualización, importancia, significados e impactos.

3. Periódicos nacionales de los años 90 s, en los que se buscó información de actividades de este tipo.

\section{Observación participante}

Se hizo uso de esta técnica ya que permitía acceder a esos significados que los sujetos negocian e intercambian, es la vivencia, la posibilidad de experimentar en carne propia esos sentidos, como sucede en la socialización (Gu- 
ber 2001, 60). Es decir, la observación permitió ver cómo se desarrollaban algunas dinámicas sociales desde los propios espacios de convivencia.

Con esta técnica se vislumbró la manera en que se construían los conciertos de ska, desde quienes son participes de ellos, considerando que dichas actividades fueron (y siguen siendo) fundamentales tanto en la reconstrucción histórica del ska como en su promoción actual.

Se realizaron 20 observaciones participantes en conciertos llevados a cabo en San Pedro (Montes de Oca), Barrio la California (San José), Zapote, San José Centro y Poás (Alajuela), durante el 2013 y 2015. Las anotaciones realizadas durante cada uno de los conciertos, fue trascrita en informes de investigación en los que se realizaron categorías y posteriormente analizados e incluidos en el artículo.

\section{Historia del ska a nivel mundial}

Como se podrá apreciar en el presente apartado, el ska es un tipo de música cuyos procesos de gestación nos remontan a los años 50 del siglo pasado. Durante su existencia, este género se ha nutrido de múltiples intercambios culturales/musicales alrededor del mundo.

Durante el proceso investigativo se hizo necesario indagar respecto a la historia del ska, con el fin de entender sus raíces geográficas, sociales y musicales. Además, una revisión historiográfica es fundamental si se quiere entender como algunos acontecimientos claves han repercutido en el baile, el ritmo, las letras y la importancia que le dieron (y aún le dan) colectivos locales e internacionales.

\section{Algunas consideraciones iniciales}

Al igual que lo proponen varias personas investigadoras en la bibliografía revisada: Fernández (2012), Quintero (2011), Roa (2011), Carballo (2001), Carballo (2006), y Marshall (1997); se entiende la historia del ska como la de un género musical de procedencia jamaiquina, el cual se desarrolla en tres etapas u "olas". Se resalta también el aporte de Kallydyr y Dalrymple (1975) en la revista "Reggae: A People's Music" quienes en el año 1974 publican un recuento histórico del ska y reggae en Jamaica desde los años cincuenta hasta 1973 y en la que además hacen una pequeña diferenciación de la historia del ska en dos etapas llamadas Primera y Segunda Ola. La "Tercera Ola" fue un agregado que vendría después a partir de aportes hechos en los años noventa y principios de los 2000 por autores como Fernández (2012) y Quintero (2011) 
Pero ¿Cuáles son los elementos fundamentales que diferencia una ola de la otra? Para poder dar una respuesta clara se decidió dar importancia a los siguientes elementos definidos por Álvarez y Obando (2017): regionalidad, temporalidad y características musicales.

Regionalidad: esta es definida por el o los lugares geográficos en los que se da una visibilidad notoria de este género musical. Se puede encontrar que la primera ola se da específicamente en Jamaica y se ve protagonizada por artistas y agrupaciones pioneras que son consideradas como "fundadoras" del género. Para la segunda ola, la mirada se enfoca en Inglaterra, lugar en el que géneros como el punk y el "new wave" tuvieron influencia en sus cambios de estructura. Finalmente, la tercera ola se caracteriza por ser la llegada de la música ska a todo el mundo, teniendo principal protagonismo otros países europeos y varios países latinoamericanos, entre ellos Costa Rica.

Temporalidad: se identifica por el año o década en la que surgió y llegó a los contextos geográficos anteriormente citados. La primera ola tiene su punto álgido entre los años sesenta; la segunda, entre principios de los setentas y finalizando los ochenta; y la tercera, del noventa a la actualidad.

Características musicales: se entienden estas como los rasgos concretos del ritmo y melodía que permiten diferenciar el ska de una ola determinada. Durante la primera ola el tempo con el que se ejecutaba el ritmo era más lento y predominaban los instrumentos de viento (trompetas, trombos, saxofones, entre otros.). En la segunda ola, empezó a mezclarse con el punk haciendo que el ritmo acelerará considerablemente. También ocurre que algunas bandas continúan incorporando sección de vientos en sus alineaciones, mientras que en algunos casos se opta por un formato "simplificado" (bajo eléctrico, guitarra, batería y voz). Finalmente, en la tercera ola se puede señalar una migración global del género musical y su fusión/adaptación a ritmos y contextos musicales sumamente diversos.

A continuación, se procede a mostrar de manera sintética información detallada respecto a cada ola del ska, la cual fue elaborada tomando en cuenta los 3 elementos previamente explicados y los aportes historiográficos encontrados en los trabajos de Álvarez y Obando (2017), Fernández (2012), Quintero (2011), Roa (2011), Leiva y Zaglul (2010) Moskowitz (2006), CarbaIlo (2001), Zúñiga (2004), Zúñiga (2006), Carballo (2006), Kauppila (2006) Marshall (1997) y Kallydyr y Dalrymple (1975).

\section{Primera Ola}

Para dimensionar la primera ola del ska es necesario fijarse en los cambios geopolíticos mundiales que ocurrieron durante los años cincuenta y sesenta. Estos años estuvieron marcados por luchas independentistas en varios paí- 
ses del Caribe que se encontraban bajo el mando de las colonias inglesas. Algunas de estas luchas concluyeron con procesos de independencia debidamente formalizados, como lo fue el caso de Jamaica en 1964.

A raíz de dichos procesos independentistas las recién formadas instituciones jamaiquinas apelaron por el optimismo y la libertad como rasgos culturales que guiarían la creación de una identidad nacional propia para diferenciarse de otros países. Este proceso viene acompañado de la necesidad de resaltar expresiones artísticas autóctonas relevantes para el pueblo jamaiquino. Sin embargo, las luchas independentistas trajeron consigo desempleo, inestabilidad económica y falta de espacios de expresión para el colectivo, lo cual pronto se vería materializado en descontento por parte de algunos sectores sociales presentes en el país, un ejemplo concreto son los rude boys ${ }^{1}$

Los rude boys solían ser grupos conformados por jóvenes negros de una posición económica baja y que frecuentemente protagonizaban enfrentamientos con las autoridades locales. Abogaban por fomentar nuevas formas de expresión de denuncia y exigían el derecho de manifestarse abiertamente. Parte de la estética que incorporaron los integrantes de este colectivo fue una adaptación de la forma de vestir de los gánsteres estadounidenses (pantalón negro, camisa blanca de manga larga, tirantes y/o corbata). Sobresalía el estampado de cuadros blancos y negros, el cual significó la unión entre las personas de piel blanca y negra.

Teniendo en cuenta estos elementos, se puede comprender de manera más amplia el contexto que rodea los inicios del ska, el cual toma gran influencia musical por parte del rhythm \& blues y el jazz, géneros musicales a los cuales tuvo acceso la población jamaiquina después del incremento de la adquisición de radios posterior a la Segunda Guerra Mundial, y medio por el cual se captaban algunas emisoras estadounidenses que programaban estos géneros musicales.

Es necesario destacar los elementos propios caribeños que influenciaron al ska, es aquí donde el calipso ${ }^{2}$ y el mento cobran gran protagonismo, siendo este último, según Kauppila (2006), un género musical folklórico de Jamaica con un gran auge en la década del 40 en la región y considerado como una de las principales influencias caribeñas en el ska.

Aquí también es necesario destacar la importancia que tuvieron los Sound Systems ${ }^{3}$, los cuales podrían ser descritos como camionetas que llevaban un equipo de sonido el cual consistía en bocinas/parlantes, micrófonos y una amplia selección musical que era reproducida en tornamesas. Los sound system solían encontrarse repetidamente en espacios públicos como plazas y parques, además era común encontrar ventas de discos de vinilo y proyección de música a todo volumen. Las personas autoras anteriormente citadas suelen coincidir repetidamente cuando se refieren al sound system como un
1. La traducción más acertada al español sería "chicos rudos".
2. Género musical desarrollado durante el siglo 17 en Trinidad.
3. La traducción más cercana al español podría ser "sistemas de sonido". 
símbolo de cohesión social que permitía la difusión de acontecimientos relevantes en el país isleño y el diálogo respecto al proceso de construcción del Estado-Nación por el cual transitaba Jamaica.

Respecto al origen de la palabra "ska", es importante destacar que hasta el día de hoy no existe un consenso de su origen, si bien autores como Kauppala (2006) aseguran que la palabra es acuñada por el bajista Cluett Johnson de la banda Clue $\mathrm{J}$ and His Blues Blasters, quien saludaba a sus amistades y llamaba la atención del público diciendo: "iHey Skavoovee!" "Love Skavoovee"; se resaltan los testimonios del productor Bunny Lee, quien asegura que la palabra fue acuñada por el guitarrista Ernest Ranglin en una sesión de grabación para describir el sonido que hacían las guitarras. Ranglin a su vez niega esta versión y dirige la responsabilidad a otro músico de apellido Smith. Otras versiones defienden que su origen se remonta a una adaptación de Byron Lee, músico pionero en el ska, a partir del término "staya staya". Kauppala reporta que otra posible versión se remonta a 1958, año en el que Lester Sterling defiende haber tenido el apodo de "Ska" Sterling debido a los sonidos que realizaba con su saxofón.

Es importante destacar que debido a la amplia variedad de instrumentos musicales utilizados era común que las agrupaciones contarán con una numerosa cantidad de integrantes. Al inicio, el ska daba énfasis a la música instrumental en donde sobresalía la utilización de trompetas, saxofón, trombones, piano, guitarra eléctrica o acústica y bajo. Sin embargo, muy rápidamente la incursión de la voz y las letras empezaron a formar parte de las canciones. Las letras tocaron aspectos coloquiales de la vida jamaiquina y representaron la cotidianidad de los rude boys; llama la atención la presencia de temáticas relacionadas a denuncias sociales y a la protesta social que capturaban el momento histórico.

Figura 1. Imagen de una partitura de guitarra con el patrón rítmico del ska.

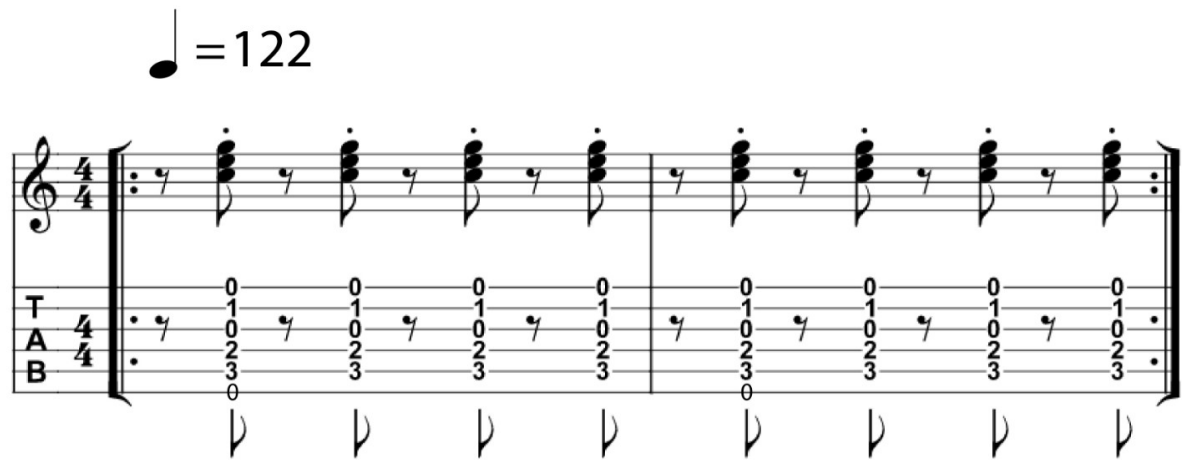

Fernando Obando 2020. 
A nivel de estructura musical, quizás uno de los elementos más distintivos del ska de esta época, es el acento en el contratiempo, el cual es marcado de manera bastante contundente por la guitarra, y la utilización de líneas de bajo caminantes o walking bass. La métrica de cada compás suele mantenerse a cuatro cuartos $4 / 4$.

Los elementos anteriormente descritos son fundamentales para distinguir al ska de sus influencias directas regionales: el mento y el calypso. Lewin (2000) brinda una definición del mento que nos puede ayudar a marcar sus diferencias:

Las canciones son en tono mayor con frases regulares que permiten la armonización por acordes primarios.

Otros acordes y modulaciones raramente son usados. Sin embargo, los ritmos pop internacionales y la popularidad del reggae han influenciado al mento y las danzas de mento. El acento del compás de 4/4 en el cuarto pulso, tiende a ser menos pronunciado, aunque los movimientos de las personas mayores (...) mantienen la acentuación tradicional... (Lewis 2000, 104).

A lo anterior Moskowitz (2006) agrega que un elemento que distingue al mento de otros ritmos contemporáneos de la época, es que el origen de este se da desde el área rural jamaiquina y no como "producto" de los ritmos que se podían ubicar en entornos urbanos. Sus raíces pueden ser trazadas hasta el siglo XIX y originalmente fue tocado con guitarra acústica, banjo, instrumentos hechos de juncos y percusión (como el cajón de rumba).

Por otro lado, el calypso de esta época, tal y como lo muestra detalladamente Charles (2016) y Moskowitz (2006) tiene una presencia importante en Jamaica, siendo este un referente de la influencia de un "género musical popular" de Trinidad y Tobago. Charles (2016) demuestra a profundidad las particularidades de este género, destacando su origen histórico, estructura y musicalización, la cual resalta por su métrica en $4 / 4$ y el uso de instrumentos como los steel drums, el banjo, las guitarras acústicas e instrumentos de percusión y de viento.

El ska se difundió rápidamente por toda Jamaica y ganó una cantidad considerable de personas seguidoras que sentían afinidades por las letras, el ritmo y su baile, el cual poseía características propias que le destacaban de otras interpretaciones dancísticas del momento. El impacto del ska en la isla fue 
tan fuerte que este consolidó las bases para el rocksteady y el reggae, géneros musicales que se desarrollarían subsiguientemente.

Algunas personas artistas y bandas más representativas de esta época son: The Skatalites, Jackie Opel, Derrick Morgan, Prince Buster, Doreen Shaffer, Laurel Aitken, Ska Campbell, Desmond Dekker, The Ethiopians, The Upsetters, Toots and the Maytals y Jah Jerry.

\section{Segunda Ola}

Al ska de la segunda ola también se le conoce como "ska two tone" Carballo (2006), Marshall (1997). La época de finales de los años 70 e inicios de los 80 es el momento más específico de expansión de este tipo de ska, teniendo una importancia relevante Jamaica e Inglaterra; coincidiendo así con varios flujos migratorios del primer país al segundo.

Temporalmente este momento concordó con el desarrollo del reggae en Jamaica, el cual tenía sus raíces en el ska, y en Inglaterra el punk y el "new wave". El ska y el punk logran identificar varios puntos de conexión rápidamente: ideales de rebelión, denuncia de falta de justicia social, llamados a la cohesión social y étnica, defensa de la clase obrera, entre otros aspectos, facilitando un acercamiento entre estos géneros musicales.

Durante este momento se consolidan y adquieren gran relevancia los cuadros blancos y negros no solo a nivel de indumentaria, sino también en los productos gráficos de las agrupaciones, los cuales representaban un llamado a la unión racial y el rechazo del racismo y el fascismo. Estos ideales se hicieron bastante explícitos en bandas que eran compuestas tanto de personas con tez negra como blanca (The Specials, The Beat, Bad Manners, The Selecter, The Bodysnatchers). Cabe también mencionar que hubo una apropiación tanto del ska como del reggae por parte de bandas inglesas las cuales estaban compuestas por personas blancas.

Como se mencionó antes el baile que acompaña al ska tiene varios pasos específicos. Durante esta época recobro gran popularidad el documental "This is Ska" (originalmente grabado en 1964) el cual recapitulaba la forma de baile y algunas presentaciones de bandas pioneras de ska. Si bien es cierto los pasos se mantuvieron en esta época, al darse el encuentro con el punk el ska aceleró su velocidad de ejecución y con ello la velocidad con la que se ejecutaba el baile.

Respecto a las letras de las canciones, si bien reflejaron temas como la unidad racial y la vida cotidiana inglesa, estas estuvieron cargadas de fuertes protestas sociales llenas de observaciones al modo de vida inglés del mo- 
mento. Quizás una de las canciones más emblemáticas de la época fue "Ghost Town" de la banda "The Specials", la cual recita:

This town, is coming like a ghost town why must the youth fight against themselves? / government leaving the youth on the shelf / this place, is coming like a ghost town no job to be found in this country / can't go on no more the people getting angry / This town, is coming like a ghost town (The Specials, Ghost town, 2 Tone Records, sencillo en vinilo de 7" y 12", 1981). ${ }^{4}$

4. La traducción al español sería: "Este pueblo se está convirtiendo en un pueblo fantasma.¿Por qué los jóvenes

Ahora bien, se puede notar que durante esta época las agrupaciones de ska mantuvieron una cantidad numerosa de integrantes y aspectos como los solos de la sección de metales (trompetas, saxofón, trombón) fueron consolidados, sin embargo, algunas agrupaciones optaron por simplificar sus alineaciones y decidieron prescindir de la sección de vientos y los teclados y simplificar su alineación a guitarra, bajo, voz y batería; mientras que otros casos se daba la inclusión de nuevos instrumentos como los "sintetizadores".

Lo anterior refleja como con la migración de personas jamaiquinas a Inglaterra, también se da el viaje del "ska jamaiquino" a este territorio. Al llegar allí se encuentra con las formas contemporáneas de la industria musical británica (principalmente la del rock y el pop), dándose un campo fértil para la combinación del ska con múltiples géneros y subgéneros musicales, como los antes mencionados. Aunado a esto, se vuelve tangible para las agrupaciones la oportunidad de pensarse en diversos formatos y con una heterogénea combinación de instrumentos.

El éxito del ska en Inglaterra fue contundente y las múltiples canciones que entraron a las listas que recogían los sencillos más populares del momento así lo demostraban: "Gangsters" y "Ghost Town" de The Specials, la interpretación de "One Step Beyond" por Madness, "On my Radio" de The Selecter, "Tears of a clown" de The Beat son algunos ejemplos de canciones con fuerte presencia en programas de música tanto radiales como televisivos.

Parece ser que hasta el momento se ha descrito un ambiente bastante prolifero para el género, sin embargo, cabe destacar que la exposición del ska en medios de comunicación masiva durante este tiempo, permitió a las personas seguidoras del género musical darse cuenta que en la mayoría de casos, las alineaciones de estas bandas eran compuestas tanto por personas blancas como personas negras. En un artículo escrito para el periódico Chicago Reader en la década de los noventa, Rodrick (1990) rescata como durante los deben luchar contra sí mismos? El gobierno deja la juventud en el estante de este lugar. Se está convirtiendo en un pueblo fantasma. No se encuentra trabajo en este país. No se puede seguir más. La gente se está enojando. Este pueblo se está convirtiendo en un pueblo fantasma". 
5. En el ámbito musical, este término hace referencia directa a una revalorización de un estilo o género musical, el cual inició su formación y desarrollo en un tiempo pasado. ochenta en Inglaterra en algunos conciertos se daban rencillas o altercados con improperios hacía las personas negras, especialmente por parte de agrupaciones de "skinheads", las cuales en algunos casos eran conformadas por personas que hacían alusiones directas al fascismo, el racismo y un nacionalismo exacerbado.

Más allá de esto, el ska siguió ganando personas seguidoras en Inglaterra, demostrando que este lugar era tan solo su primera parada en territorio europeo, pues este género musical estaba a punto de hacerse conocido en todos los rincones del continente y en otras partes del mundo con las que apenas se empezaba a generar un tímido contacto.

\section{Tercera Ola}

A partir de mediados de los 80 y los años 90 el ska empieza a emigrar rápidamente por diferentes latitudes: el resto de Europa, Latinoamérica, Estados Unidos, Rusia, Japón, Australia, entre otros lugares. Cabe destacar que el ska empieza a familiarizarse también con los géneros musicales pertenecientes a cada región particular y empieza a sufrir un sinfín de adaptaciones y transformaciones en su baile y ejecución. A esto le llamamos "la tercera ola del ska".

Según Zúñiga (2006) para el caso latinoamericano tiene especial impacto las bandas mexicanas, españolas y argentinas que empiezan a visibilizarse, pues estas mostraban el sincretismo musical que era posible alcanzar con el género, dándose rápidamente combinaciones con cumbia, rock, salsa, funk, murga, corridos, entre otros géneros.

Cabe destacar que, si bien es un momento en donde se empiezan "a romper todas las reglas" del ska, hay elementos que se mantienen como el acento del contratiempo con las guitarras y las líneas de bajo caminantes los cuales han sido elementos fundamentales para que el género guarde conexión con sus raíces. También es cierto que las alineaciones de las bandas se volvieron más pequeñas o de lo contrario, más grandes por medio de la inclusión de nuevos instrumentos (acordeones, sintetizadores, congas, timbales, clarinetes, tubas, organetas, mandolinas, cuatro, tres, entre muchos más), pero también se pudo observar que algunas agrupaciones no se sintieron cómodas con este eclecticismo musical, o en su defecto buscaban dar espacio a versiones más "tradicionales" del ritmo, por lo que se dice que dentro de la tercera ola también hubo un "revival" ${ }^{5}$ de la primera ola del ska.

Algunas bandas importantes de destacar en esta época son: The Toasters, Less Than Jake, Reel Big Fish, The Mighty Mighty Bosstones, Goldfinger (Estados Unidos), Ska-P, Skalariak, The Locos (España), Talco (Italia), Tokyo Ska Paradise Orchestra (Japón), Los Fabulosos Cadillacs, Los Caligaris (Ar- 
gentina), Panteón Rococo, La Maldita Vecindad y los Hijos del Quinto Patio, La Tremenda Korte, Inspector, Sekta Core, Maskatesta (México), La Vela Puerca (Uruguay), Doctor Krápula (Colombia), El Guato, Los Garbanzos (Costa Rica) entre otras.

Previamente Álvarez y Obando (2017) mencionan que el hecho de que a través de la música los colectivos jóvenes pudieran expresarse y denunciar, además de encontrarse un ritmo alegre que lograba combinarse con los ritmos regionales, fueron factores decisivos para su expansión.

Para Roa (2011) la adaptación a las vivencias colectivas de cada zona geográfica, y las narrativas de rebeldía y descontento social fueron factores que el ska logró mantener, lo cual facilitó que fuera adoptado por colectivos jóvenes que se encontraban en procesos de formación identitaria en los cuales se mostraba una clara oposición a ideologías dominantes e injusticias sociales en sus diversas dimensiones.

Parece ser que una pregunta valida en este momento es ¿Se puede hablar de una cuarta ola de ska? Artículos periodísticos como los que se pueden encontrar en The Economist "A fourth wave? Ska still has things to say" (2019) o en Billboard "Ska Lives: How the Genre's Fourth Wave Has Managed to Pick It Up Where the '90s Left Off" por Jessica Lipsky (2019), buscan iniciar discusiones respecto a esta noción. Una revisión del estado del ska contemporáneo será necesaria, además de tener claro cuáles son las tendencias musicales que están incorporando las bandas de ska actuales y cómo ha sido la transformación del género durante el siglo 21.

\section{Historia del ska en Costa Rica}

En Costa Rica el ska empieza a hacerse visible durante los noventa, justo en el apogeo de la tercera ola a nivel mundial, y en donde dialogaba con el contexto y algunos ritmos latinoamericanos, además de la visible influencia del punk, con el cual compartía similitudes en cuanto abordajes de temáticas en las letras.

Fue así como a mitad de los años noventa empezaron a surgir en la escena musical costarricense bandas de punk como Niño Problema, El Bosque e Hijos de la Adversidad, las cuales fueron pioneras e incentivaron a que otras personas también realizaran o promocionaran nuevas bandas musicales de géneros similares. Como lo mencionan Geovanni Durán y Esteban Rodríguez, en la entrevista realizada por Álvarez y Obando (2018),

El lapso sería como más o menos 94 bueno sí, el 94 que empecé con Niño Problema y ya existía El Bosque. Como 
el 97 que ya empezó El Guato, que empezó un grupo que empezó netamente de ska. $Y$ de ska punk y que estaba existiendo ya Calle Dolores, Mod-ska y Garbanzos como tales. Mentados iba mutando ahí, se llamaba Mentados Paupérrimos, y ellos iban mutando como del punk al ska (Comunicación personal 16 de abril del 2015).

También Esteban Rodríguez, integrante de Seka, agrega:

Exactamente, yo la versión que tengo desde el 95 para acá que andaba dando vueltas, haciendo feo. Entiendo que la primera banda de Ska... Bueno ahí un movimiento pre lo que ya conocemos que es antes de la generación del 95' para adelante; que es de música original, que estoy hablando básicamente, que es los Hijos de la Adversidad que es la primera banda de Punk que es con lo que se conoce (Comunicación personal 29 de agosto del 2014).

Si bien, se puede hablar de que las bandas procedían de diferentes lugares, destaca la similitud con géneros como el metal (Corrales 2011), el rock (Zúñiga 2006), el punk (Fuentes 2004) y el ska (Carballo 2006) donde su nacimiento, o primeras promociones, surgen en algunos barrios ubicados al sur de San José, o mejor conocidos como "Barrios del Sur", los cuales comprenden: Alajuelita, Desamparados, Hatillo, Distrito Hospital, San Sebastián.

Estas zonas no solo son cercanas geográficamente, sino que también comparten características similares, relacionadas con la vulnerabilidad económica, social y política, manifestada por el hacinamiento, toma de tierras ilegales, violencia, venta de algunas drogas, infraestructura de viviendas y comunal en mal estado, deficiencias en algunos servicios básicos, entre otros. Si bien, durante los noventa surgieron diferentes medidas para la atención de dichas problemáticas, como las tomadas por el Instituto Nacional de Vivienda y Urbanismo (INVU) y del Instituto Mixto de Ayuda Social (IMAS), la solución era meramente paliativa, lo cual provocada el descontento de quienes vivían allí (García y Paniagua 2009). 
A pesar de dichas condiciones, surgieron algunos espacios para la recreación y deporte los cuales eran utilizados principalmente por jóvenes de estos lugares. Se tiene así la apertura del primer parque de skate ${ }^{6}$ en Hatillo, de- 6. Abreviatura de porte que para el momento guardaba cierta relación con el ska, debido a que skateboarding deporte en el muchos de los vídeos de personas pioneros de este deporte, como lo son eran Chad Muska, Tony Hawk y Rodney Mullen, estaban musicalizados con ska.

mismo tiempo pueden realizar

Sucede entonces que estos videos son reproducidos también en Costa Rica, volviéndose populares entre las personas de ese lado de la ciudad, fomentando así no solo el deporte, sino que también el ska. Como lo reafirma el vocalista de El Guato en las entrevistas realizadas por Álvarez y Obando (2018):

(...) que yo supe por primera vez de ska con una banda costarricense, fue El Bosque, era un grupo de Hatillo, era un mae de San Sebas, uno de Hatillo y otro de Alajuelita; la vara es que esos maes siempre estaban en todas, estaban en todas con el skate, y estaban en todas con la música, entonces ellos ya conocían el ska (Comunicación personal 16 de abril del 2015).

Agrega Esteban de la agrupación Seka:

(...) Como que hubo una vanguardia ligado al Skate. Todas estas bandas de ska, todos patinaban. Usted va y se fija y el primer lugar que se patinaba que hay en Costa Rica está en Hatillo (Comunicación personal 29 de agosto del 2014).

Aquí es necesario reflexionar sobre la importancia que tuvieron (y aún tienen) los jóvenes en la apertura, la readaptación y la apropiación de diferentes espacios públicos urbanos, esto por medio del arte y deporte, lo cual se ha convertido en una manera de hacer valer el derecho a la cultura, a la recreación y a la ciudad, de ahí que también es una manera de mejorar la calidad de vida de quienes están en dicho espacio. Asunto que también rescata Gravano, quien afirma que acciones como estás constituyen: "la reivindicación de quienes, en ejercicio del derecho ciudadano a vivir en condiciones dignas, 
a consumir la ciudad que producen, aspiran a cambios que brinden mejoras a los modos en que se vive, usa y consume el espacio urbano" $(2013,76)$.

Esto se ve demostrado en la manera en que los y las jóvenes, a pesar de las condiciones socioeconómicas y físicas de su entorno para ese momento, se apropiaron de un espacio como lo era el skate park y de ahí empezaron a surgir nuevas manifestaciones artísticas, las cuales, muchas veces, aludían a dicha realidad.

Continuando con el recuento histórico, se tiene que la música ska empieza a ser visible también en otros medios y espacios. Fue así como algunos jóvenes empezaron a compartir e intercambiar música grabada en casetes, especialmente de bandas procedentes de México, España y Argentina, las cuales compartían la particularidad en cuanto ritmo, mensaje e ideología manifestada en la letra, como lo menciona Moritz, integrante de la banda UFO en la tesis de Álvarez y Obando (2018):

(...) entonces se pasaba música di ahí de grupos que no eran muy populares digamos de Argentina, de México, de Inglaterra, de Estados Unidos bastantes. La música se pirateaba mucho, entonces, ya digamos la gente que le gusta el punk, el ska o el ska-punk o géneros así digamos, que eran poco populares verdad o que no se escuchaban en la radio verdad, entonces esa música iba a parar a la gente que le gustaba, la gente que le gustaba la buscaba. Entonces verdad uno di depende de los amigos que uno tuviera, a uno le empezaba a llegar ese tipo de música y uno se empezaba a mojar más en lo que era esa música y el movimiento verdad que venía con ella, porque también por eso digamos, me llamó la atención, porque digamos como que ska empecé a escuchar como Maldita Vecindad, Los Fabulosos Cadillacs, Los Calzones Rotos, que eran bandas que eran muy buenas, pero no eran como... verdad estaban saliendo apenas, entonces uno escuchaba que tenían un mensaje diferente o sea que no eran... grupos como Todos tus Muertos que 
también tocaban ska digamos, como que adoptaron el ritmo ska como una opción también como alegre, como de compas me entiende, porque es un ritmo muy alegre ya, es un ritmo que di para echarse las birras con los amigos, bailar, chingar entiende, es vacilón, por eso empecé a escuchar ska (Comunicación personal 28 de agosto del 2014).

Algunos de estos casetes eran compartidos por personas que habían logrado viajar al extranjero, o bien, por encargo a otros. Se presentó también la peculiaridad de que Geovanni Durán (pionero en este género) trabajó en una tienda musical donde solían vender vinilos, casetes y VHS, siendo más fácil el acceso a nuevas bandas y sellos discográficos que promovían géneros como el ska y el punk. Posteriormente, esta música la solía compartir con otras personas que sentían agrado por la misma.

Es importante hacer notar un punto, y es que la socialización de la música, en ese momento, se hizo por medio de casetes regrabados a partir del original, donde si se toma en consideración aspectos como lo empresarial y legal, se incurrió en la piratería, entendida esta como una falta ante los derechos de autor (morales y patrimoniales) y al derecho que tiene el sello discográfico sobre los discos.

Si bien, no era legal, ni la calidad era la óptima dado que eran casetes grabados de otros que también lo fueron una gran cantidad de veces, la piratería fue un medio de distribución musical dado que permitió que tanto el ska como otros géneros musicales empezaran a ser conocidos y compartidos por algunos jóvenes. Además, por medio de esta práctica, aquellas personas que no tenían el poder adquisitivo para obtener un casete original podían acceder a la música del momento; es decir, la piratería: "simplemente le da a alguien acceso a algo a lo que, según las leyes, no debería tener" (Lessing 2005, 83).

Ahora bien, otro de los medios que tuvieron gran impacto durante ese tiempo en cuanto a dar a conocer y distribuir música, fue "Radio U" emisora de la Universidad de Costa Rica, la cual tiene como principio la promoción de música popular, especialmente costarricense. Aquí se promueven géneros como rock, ska, punk, metal, reggae, entre otros. Por ello surgieron programas como: Música por Inclusión, Punto de Garage y Exhum, los cuales resaltaban por promover géneros que estaban recién emergiendo. Moritz, baterista de UFO, comenta (Álvarez y Obando, 2018): 
Moritz: Diay si no, ya después del casete se vinieron los CD's y después ya vinieron a andar en algunos programas de radio como Punto de Garaje, Radio U, Música por Inclusión de la UCR también, muchos medios de la UCR empezaron a ayudar a la escena nacional digamos en esto de la música nacional; bueno de la música en sus géneros digamos como de todo. Bueno siempre han ayudado en todo lo comercial y clásico, pero sí, hubo muchos programas que ayudaron a que la música nacional saliera, entonces se difundía mucho la música ahí (...) digamos Punto de Garaje duro como más de diez años ayudando a lo que era el género así underground, así grabo a grupos como Seka, grabó a UFO, grabó..., ayudo a todo mundo entiende (Comunicación personal 28 de agosto del 2015).

El impacto de Radio U radicaba en el apoyo al artista nacional, pero este no se limitaba solamente a la exposición de la música en los programas, sino que también trabajaron en la grabación, masterización y distribución del material de algunas bandas.

Si se remite a la historia del ska en Jamaica, se puede decir que Radio $U$ viene a ser los Sound Systems de Costa Rica, al ser un medio de distribución de la música en diversos espacios. El ska empezaba a tener mucha presencia entre los jóvenes, pero no era acogido por otros medios de comunicación, por lo que Radio $U$ era una forma de que estos pudieran mostrar el material que estaban ejecutando o bien, conocer más sobre la escena musical costarricense.

En cuanto los espacios de promoción del ska, se tiene que muchos jóvenes se empezaron a reunir en lugares como colegios, casas, aceras, entre otros, tanto para intercambiar música, como para discutir sobre las letras, las cuales se caracterizaban por ser críticas ante cuestiones políticas y sociales. Es así como se empieza a gestar espacios de discusión, convivencia y cohesión social.

La promoción del ska en estos espacios provocó que muchos jóvenes empezaran a formar sus propias bandas, con las cuales no solo promocionaban un 
género musical, sino que también mostraban la realidad social en la que se encontraban, esto por medio de la críticas que había en las letras. Fue así como en los noventas surgieron bandas como: Mod-Ska, Calle Dolores, Tropa 56, Tetra, Mentados, Niño Problema, Garbanzos, Seka, UFO, El Guato, entre otras, las cuales fusionaban el ska con otros géneros. Muchas de estas bandas iniciaron siendo de garaje, para luego convertirse en referentes de la música nacional costarricense. Inclusive algunas de estas aún están activas.

Con el auge de nuevas bandas, también vino la promoción de los chivos, es decir, de conciertos pequeños llevados a cabo en diversos espacios, donde se presentaban algunos artistas. Aquí resulta interesante hacer notar que las dinámicas del concierto iniciaban antes de que abrieran las puertas de lugar, justamente en los espacios donde se tenía que hacer fila para entrar. Allí se conversaba, se compartía nueva música, se conocían personas, y se consumía alcohol. Más que ser un espacio de paso, era uno de convivencia, una antesala para la actividad principal: las presentaciones en vivo.

Como se mencionó anteriormente, los chivos no eran solamente de ska, allí confluían con géneros como punk, metal y rock; situación que caracterizó también la tercera ola del ska a nivel histórico. Aquí estos géneros no competían, sino que dialogaban y se acompañaban, como lo comenta Geovanni Durán (Álvarez y Obando 2018):

(...) porque muchos géneros se unían, porque solo había un solo lugar, entonces todos los rockeros éramos rock, no importa si era rock, si era metal, si era ska, lo que sí estaba un poquito más separado era lo que le decíamos rock alternativo, por lo menos yo que era el que hacía los eventos, hacía un grupo de metal, otro de punk, ska, incluso un poco de grunge (Comunicación personal 16 de abril del 2015).

El chivo representaba un espacio para el disfrute y la convivencia social, aquí la exposición musical de bandas emergentes permitió (y aún lo siguen haciendo) que los jóvenes pudieran expresarse desde formas que en otros contextos (hogar, trabajo, escuela) no eran permitidos o bien, eran señalados. Aquí podían conversar de música, de política, de la sociedad, de la vida, de ideales, desde una manera crítica. Todo lo anterior acompañado de música y baile. 
Un aspecto fundamental durante los conciertos era el baile, el cual nace durante la segunda ola del ska, convirtiéndose en una forma de exteriorizar de manera corporal lo que la música provocaba. En sus inicios el baile se presentaba por una serie de movimientos similares al del soul, mientras que conforme pasaban los años, surgían nuevas bandas y estas fusionaban otros ritmos, por lo que el baile empezó también a ser más fuerte, donde se simulan algunas acciones similares a los golpes, pero sin que estas fueran intencionales o tuvieran la pretensión de golpear a alguien.

Ahora bien, dado que los chivos de ska fueron más recurrentes, es que empezaron a surgir al mismo tiempo, lugares que permitirían la realización de estas actividades. Un asunto particular es que estos espacios no siempre se ajustaban a las necesidades de un evento en vivo en cuanto escenario, acústica, etc., ya que se encontraban adecuados a otros tipos de usos: comercial, educativa, entre otros.

En parte, la escogencia de estos lugares se debía a que había pocas opciones para la promoción de presentaciones en vivo, fue así como los integrantes de las mismas bandas identificaban el lugar, le exponían el tipo de actividad a la persona dueña y le pedían permiso para realizarla allí. Algunos aceptaban la propuesta, mientras que otros aún mantenían ciertas reservas en cuanto a los chivos.

Algunos de estos lugares se volvieron puntos de referencia en cuanto chivos se trataba, destacaban: la Rana, Cus, la Alianza China, el Tablado, El Pueblo, Sand, todos estos en San José; o bien La Finca, en Cartago.

Un asunto particular de estos sitios eran los cambios en los usos debido, mayoritariamente, a razones comerciales y de patentes. Un negocio podía en un momento ser un bar y en otro ser una iglesia, y así sucesivamente. Por ejemplo, las personas entrevistadas comentaban que el bar Cus, paso a ser Kiss, luego Acapulco (ambos bares) y luego una pasamanería; la Rana pasó a ser The Horny Toad y después un restaurante de comida folclórica; pizzería Valerio's tuvo un local en el ya desaparecido centro comercial Cocorí en Los Yoses; Troys fue posteriormente un burdel y una soda; Vikingos se convirtió en una iglesia evangélica; y así sucesivamente.

Con el cambio de uso de estos sitios, venía también el de lugares donde se hacían los conciertos. Si bien acá la mayoría fueron en la Gran Área Metropolitana (GAM) dada las facilidades en cuanto acceso, disponibilidad de espacios, transporte, etc., hubo algunos que se llevaron a cabo fuera de esta región y que igualmente tuvieron una buena acogida por parte de las y los seguidores del ska. Era tan fuerte el apoyo en ese momento, que cuando se anunciaba un concierto de esta índole, las personas se organizaban semanas antes y alquilaban una buseta que los lleva desde ciertos puntos de la 
GAM hasta el lugar del chivo y viceversa. Como lo comenta Geovanni Duran, del Guato (Álvarez y Obando 2018):

(...) entonces de la finca era la finca, entonces salían hasta 5 buses desde San Pedro y 3 de Heredia, y uno vacío de Alajuela que tenía que pasar por Heredia para rellenar los campos que faltaban, entonces digamos como que esa es la parte que de la finca... (Comunicación personal, 16 de abril del 2015).

Fue así como poco a poco los chivos de ska fueron convirtiéndose en espacios de suma importancia para los y las jóvenes, ya que estos se presentaban como espacios donde no eran juzgados y se compartía la forma de vestir, pensar y actuar. Según las personas entrevistadas, en los chivos, la edad, la situación socio-económica o educativa era indiferente, ya que en los conciertos de manera recurrente se manifestaba que todos y todas eran iguales y tenían la misma oportunidad de poder pronunciarse, denunciar y exteriorizar su aprobación o descontento con ciertas situaciones.

Lamentablemente, uno de los hechos que tuvo un impacto en cuando chivos e historia del ska se trata, fue el cierre de La Finca en el 2007, lo cual hizo que los conciertos se concentraran, en su mayoría, en San José. Surgiendo lugares como Club Capone, Latino Rock Café, San Lucas, Manhattan y Acid Bar.

Sobre el asunto de los chivos es necesario reflexionar acerca de la importancia que tenían (y siguen teniendo) estas actividades para el público seguidor de ska (y otros géneros musicales). Como se comentó anteriormente, algunos de los lugares donde se llevaban a cabo estas actividades no contaban con las condiciones físicas para albergar una actividad como esas, dado que eran pequeños, solo contaban con una salida, no tenían plantas de sonido, entre otros, sin embargo, muy a pesar de las condiciones, los chivos se convirtieron en espacios significativos para quienes asistían, dadas las siguientes razones:

\section{El chivo como espacio de pertenencia grupal}

Aquí era evidente el sentido de pertenencia que se generaba en este espacio, dado por la interacción con otras personas con las que se coincide en cuanto música, ideologías, identidad y en las formas en las que se actuaba y expresaba. Rescatando a Reguillo (2000), en el chivo más que haber un "otro", había un "nosotros", dado que son espacios de pertenencia y adscrip- 
ción identitaria, a partir de los cuales es posible generar un sentido en común sobre un mundo incierto. (Reguillo 2000, 03).

Quienes asistían (y asisten) son conscientes de que en un mismo espacio confluye la música, el baile y las personas, estas pertenecen a un grupo en los que no se les va a juzgar por su apariencia física o ideológica. Ahí se socializa, se siente y vive la música. Es por eso que el chivo se convirtió en un espacio de confrontación y quiebre entre lo que se cree y lo que el resto de la sociedad expresa y espera de cada uno los que allí se encuentran.

\section{El chivo como fiesta}

El chivo también fue (y sigue siendo) un espacio para el disfrute y la recreación, el cual puede estar suscrito a un ámbito de informalidad, asunto que se ve aún hoy en día. Cabe el ejemplo de un chivo llevado a cabo en Acid Bar, donde las personas asistentes instalaron una parrilla afuera y empezaron a cocinar como si se tratara de una reunión familiar.

El hecho de que sea un momento festivo hace permisible y normaliza asuntos como el baile y el consumo de alcohol, o inclusive de substancias que suelen ser chocar con disposiciones legales, como la marihuana y la cocaína. Sin embargo, el chivo, es al mismo tiempo una forma de tomar una pausa ante la cotidianidad del trabajo, estudio, vida familiar $u$ otras labores.

Otro asunto que lo caracteriza como festivo es la permisibilidad en cuanto a la crítica que se les hace a cuestiones como política, gobierno, policía, iglesia, sexo, etc., que en otros espacios no es bien visto o que del todo no se hablan. Muchas de las cuales se manifiestan por medio de conversaciones o las letras de algunas canciones. Ejemplo de ello es la siguiente canción de la banda SEKA, llamada "No vuelvo más", la cual critica la represión por parte de algunas entidades y como algunas personas prefieren ir contra de dichos sistemas:

(...) ¿Por qué la delincuencia? ¿Por qué lo marginal? I ¿Por qué los niños mueren en la guerra sin parar? / Yo no encuentro nada que me haga cambiar / Vivimos en un país que es una jaula de metal / Por eso yo no vuelvo más / Por eso a mí iglesia no vuelvo nunca más / Nos encierran en una jaula de metal y nunca nos enseñan a opinar / Por eso yo no vuelvo más / Por eso a mi casa no vuelvo nunca más / Nos encierran en una jaula de metal / 
Y nunca nos enseñan a opinar... (SEKA, No vuelvo más, La Golondrina Records, disco compacto, 2002 )

Ahora bien, aquí es necesario rescatar que quienes asisten a los chivos no se mantienen pasivos, todo lo contrario, son activos en cuanto todo lo que hacen, es decir: consumen, cantan, hablan y bailan. Este último es importante dado que funciona:

(...) como rito de competencia entre los jóvenes, como un combate ritual que manifiesta valor, violencia, y cohesión social dentro del grupo (...) los movimientos de los danzantes se ejecutaban con un pacto de inicio implícito y conjunto, donde las manifestaciones del cuerpo se combinan en forma simultáneamente (sic) y diferente, pero acordes con los exabruptos musicales (Fuentes 2004, 138-139)

El Slam, como se le llama al baile grupal del ska, no es un conjunto de pasos que deban marcarse al compás y de manera coordinada, sino que constituyen una experiencia corporal de movimientos violentos en los que no se golpea a nadie de manera intencional y que, en conjunto con la música, luces y gritos, representa una manera de liberación y de conquista ante las (re)presiones y relaciones impuestas por la sociedad.

\section{El chivo como espacio para la expresión musical}

El chivo es la presentación musical de un artista o una banda, por lo que también es un espacio artístico. Por medio del ska, el artista tiene la posibilidad de mostrar a su público, su propia realidad social, pero también le permite desarrollar su creatividad individual y colectiva por medio de la ejecución de un instrumento (desde guitarras, trompetas, batería, etc.), de la composición de letras y música, y del montaje de espectáculo.

Para el caso del ska, dicha función del chivo es de suma importancia pues permite también a las personas interpretes observar la ejecución del género musical por parte de integrantes de otras bandas y las formas de experimentación musical empleadas, las cuales, como anteriormente se mencionó, contribuyen a la transformación musical del ska. Parte de dicha expresión musical también es representada en las letras, que en reiteradas ocaciones dan pie a discusiones sobre diversos temas entre las personas ejecutantes. Final- 
mente, dicha dimensión puede verse materializada en las producciones discográficas de las agrupaciones que participan del chivo (cassetes, cd's, vinilos, tarjetas de descargas digitales, etc.), las cuales suelen venderse exclusivamente en los conciertos y representan una forma de acercarse a los pormenores conceptuales de las obras expuestas por las personas ejecutantes; esto sin dejar de mencionar que también son una entrada importante de recursos que en muchos casos permiten algún grado de sostenibilidad de los proyectos musicales

\section{Conclusiones}

A lo largo de los apartados anteriores, se pudo observar como el ska, contó con la versatilidad de adaptarse al contexto social, cultural y artístico de las regiones a las que llegó, asunto no solo propio a nivel mundial, sino también a nivel local.

Se tiene así que este género musical, que lleva más de 60 años de trayectoria, es un espacio de testimonio sonoro y artístico que conmemora la herencia musical afrocaribeña y lleva a un momento específico de los procesos históricos jamaiquinos.

Su adaptabilidad permitió que poco a poco fuera llegando a múltiples latitudes, permitiendo así su mezcla con un sinfín de expresiones musicales, pero conservando algunos elementos propios de su estructura musical y en la forma de ejecución instrumental, cuestiones particulares de la primera ola.

Para el caso particular de Costa Rica, el contexto histórico permitió vislumbrar como el ska estuvo ligado a un grupo juvenil que se encontraba en un contexto de vulnerabilidad, dado por lo económico, social y político, propio de los Barrios del Sur. Sin embargo, dicha situación llevó a estos grupos a reclamar y abrir espacios para la expresión artística, manifestada por medio de un género musical especifico: el ska.

Cabe mencionar que esta construcción histórica no es exclusiva del ska, sino que forma parte de una escena de "música alternativa", donde se comparten cuestiones relacionadas con la gestión de actividades y la participación de colectivos juveniles. Los principales puntos de convergencia se localizan con géneros como: rock, punk, metal, reggae y la música experimental.

En esta misma línea, el ska funciona como un "vehículo" para entender las relaciones que surgen con otros géneros musicales, a la hora de analizar, en términos de estructura, las canciones que tocan estas bandas. También el asunto de que al ser una comunidad musical alternativa y relativamente pequeña, hay constantes guiños y referencias a otros géneros musicales, lo 
que permite trazar históricamente las interacciones que se dan en otros contextos musicales locales.

El espacio del chivo como un lugar de convivencia de géneros musical y un espacio vital para el desarrollo del ska y sus aspectos identitarios, con los que se ven identificadas las personas seguidoras. Si se revisan los testimonios y la música de las personas que participaron activamente en la formación de esta escena a nivel local, se nota que se comparten temáticas/relaciones que el ska ha desarrollado a lo largo de la historia (unión "racial"/ protesta social / cotidianeidad), siempre teniendo en cuenta que surgen adaptaciones propias.

Este momento del desarrollo del ska en Costa Rica, vive una tensión: el vivir asociado a una escena música "Alterativa" o contestaria, o involucrarse en aspectos propios de la industria musical, como se le entiende internacionalmente, e inclusive haciendo referencia al éxito que tuvo el ska en medios de comunicación masivos en el reino unido en los 80 y en Estados en los 90. Este choque es identificado en el momento en que personas entrevistadas hacen referencia a bandas que "se vuelven comerciales" para referir su asociación con algunos patrocinios de marca o cambios en su estilo musical. Se identifica este como uno de los aspectos a profundizar con agrupaciones participantes en el desarrollo de la escena musical de la época.

Ahora bien, el contexto sociocultural y/o la gestión cultural de la música, a lo largo de los años, ha variado significativamente, impactando así en la escena musical del ska (y otros géneros), lo cual lleva a reflexionar y ha realizar algunas preguntas:

1 ¿Qué ha pasado desde la última vez que las personas investigadoras presentaron los resultados de su trabajo? Algunos eventos como el Finca Fest, en el 2020 llamaron la atención dado la poca presencia de "bandas nuevas", pero si se observaron muchas que aún se encuentran activas, las cuales iniciaron su trayectoria desde los años noventa o inicios de los 2000.

2 El 2020 se presentó la situación de la pandemia por la enfermedad COVID-19, afectando no solo a nivel de salud, sino también otros contextos como el artístico, por lo que surgen las preguntas ¿Cómo afecta "los tiempos" de pandemia al ska? Si no hay chivos ¿dónde suena el ska? ¿Cómo será el regreso del ska a los escenarios y cómo afectará su desarrollo histórico?

3 En cuanto aproximación metodológica, surge la interrogante ¿Qué aspectos importantes se deben tomar en cuenta si quiere investigar su desarrollo a nivel local y/o Latinoamericano? ¿Cuáles son los géneros 
musicales locales a los que se debe poner atención si se quiere entender mejor su versatilidad?

4 Pensando en el surgimiento de nuevos contextos artísticos y regionales, surgen interrogantes como: ¿Existe una cuarta ola? ¿Cómo sería esa cuarta ola? Si se parte de los elementos de regionalidad, temporalidad y características musicales: ¿Ha cambiado algo? ¿Cómo se oye el ska en el mundo? ¿Se continua aún en una tercera ola?

\section{Bibliografía}

Álvarez López, Jessica y Fernando Obando. 2017. «Juventud y chivos de ska: una forma de gestión cultural alternativa». Cuadernos de Antropología 27 (1): 1-19.

Álvarez López, Jessica y Fernando Obando Reyes. 2018. «Juventud y chivos de ska: una forma de gestión cultural alternativa». Tesis de Licenciatura. Universidad de Costa Rica.

Camacho Navarro, Donovan. «Ska, calle y memoria». La Milixia, 2011, $1 \mathrm{~cd}$. Fecha de grabación desconocida.

Carballo Villagra, Priscilla. 2001. «Cantar y Contar: un estudio cualitativo de la música como generadora de espacios de interacción de la juventud popular». Tesis de Licenciatura en Trabajo Social. Universidad de Costa Rica.

Carballo Villagra, Priscilla. 2006. «La música como practica significante en los colectivos juveniles». Revista de Ciencias Sociales 3(113-114): 169176.

Charles, Clarence. 2016. «Calypso Music: identity and social influence, The Trinidadian experience». Tesis de Doctorado. Universiteit Leiden.

Corrales Ulate, Rafael. 2011. "Camisetas Negras, una experiencia alternativa: estudio sobre el movimiento metalero urbano en Costa Rica». Tesis de Maestría en Antropología Social. Universidad de Costa Rica.

Dammers, Jerry. "Ghost town». The Specials, 1981, sencillo de vinilo de 7" y 12". Grabado del 3 al 9 de abril y del 15 al 17 de abril de 1981. 
Dannenberg, Roger. 2009. "Style in music». En The Structure of Style: Algorithmic Approaches to Understanding Manner and Meaning, Editado por: Argamon, Shlomo, Burns, Kevin, Dubnov, Shlomo, p.4458. Berlin: Springer-Verlag

Fernández Monte, Gonzalo. 2012. «El Ska en España: Escena alternativa, musical y trasnacional». Tesis Doctoral en Musicología. Universidad Complutense de Madrid.

Fuentes Rodríguez, Laura. 2004. «La construcción simbólica del "underground" goth y punk en la juventud del área urbana costarricense». Tesis de Licenciatura en Comunicación Colectiva con énfasis en Periodismo. Universidad de Costa Rica.

García Fernández, Raúl y Laura Paniagua Arguedas. 2009. «De La Puebla a La Carpio: segregación y exclusión en la ciudad de San José». Diálogos Revista Electrónica 9:1483-1509. DOI 10.15517/DRE.V9I0.31249

Gravano, Ariel. 2013. Antropología de lo Urbano. Buenos Aires: UNCPBA.

Guber, Rosana. 2001. La etnografía. Método, campo y reflexividad. Buenos Aires: Siglo Veintiuno Editores Argentina S.

Kallyndyr, Rolston y Dalrymple, Henderson.1975. Reggae: A People's Music. Londres: Carib-Arawak Publications.

Kauppila, Paul. 2006. «From Memphis to Kingston: An Investigation into the Origin of Jamaican Ska», Social and Economic Studies (55): 75-91.

Leiva López, Priscilla y Layla Zaglul Ruiz. 2010. «Descifrando los sonidos simbólicos de Cahuita: un acercamiento a la realidad de los jóvenes por medio de la música que escuchan». Tesis de licenciatura en Antropología Social. Universidad de Costa Rica.

Lipsky, Jessica. 2019. «Ska Lives: How the Genre's Fourth Wave has Managed to Pick Up Where the '90s Left Off». Billboard, https://www.billboard.com/articles/columns/rock/8508727/ska-livesfourth-wave-interrupters-pick-it-up

Lessing Lawrence. 2005. «Cultura libre: Cómo los grandes medios usan tecnología y las leyes para encerrar la cultura y controlar la creatividad». Santiago: LOM Ediciones.

Lewin, Oliver. 2000. Rock it come over, The Folk Music of Jamaica. USA: University of the West Indies Press. 
Marshall, George. 1997. The two-tone story. Escocia: ST Publishing.

Moskowitz, David Vlado. 2006. Caribbean Popular Music. Westport, Connecticut: Greenwood Press.

Quintero Palacios, Katherine del Mar. 2011. «Hasta la victoria siempre: Afinando las guitarras contra toda presión, el ska una forma de resistencia anti-sistema en Colombia». Proyecto de Grado de Ciencias Políticas con énfasis en Relaciones Internacionales. Universidad ICESI.

Recalculando. 2017. «Sellos de gestión colectiva». En Guía Rec. Editado por Martín Mena y Bruno Maccari. Buenos Aires: Ministerio de Cultura de Argentina.

Reguillo Cruz, Rosana. 2000. Emergencia de culturas juveniles, estrategias del desencanto. Buenos Aires: NORMA.

Roa Garzán, María de los Ángeles. 2011. «El discurso del Ska y el reggaetón: ideología vs. Emotividad» Tesis de Licenciatura en Humanidades y Lengua Castellana. Corporación Universitaria Minuto de Dios.

Rodrick, Stephen. 1990. "Ska story: the sound of angry young England». Chicago Tribune https://www.chicagoreader.com/chicago/ska-story-thesound-of-angry-young-england/Content?oid $=875398$

Seka. «No vuelvo más». Seka, 2002, 1 cd. Grabado entre setiembre y octubre del 2002.

The Economist. 2019. "Ska still has things to say». The Economist. https://www.economist.com/prospero/2019/02/04/ska-still-has-things-tosay

Zubiría Samper, Sergio, Ignacio Abello Trujillo y Marta Tabares. (1998) Conceptos básicos de administración y gestión cultura. Madrid: OEl.

Zúñiga Núñez, Mario. 2004. «Apuntes iniciales acerca de la escena de música popular juvenil costarricense». Revista Centroamericana de Ciencias Sociales 1(1), 161-182.

Zúñiga Núñez, Mario. 2006. Cartografías de otros mundos posibles: El rock y el reggae costarricense según sus metáforas. Heredia: EUNA. 